\title{
A TEORIA DA ATIVIDADE E O ENSINO DE HISTÓRIA: PERSPECTIVAS NO ENSINAR E APRENDER
}

\author{
Maria da Paz Cavalcante \\ Universidade do Estado do Rio Grande do Norte - UERN \\ mariadapazc@yahoo.com.br \\ Francisca Lacerda de Góis \\ Universidade Federal do Rio Grande do Norte - UFRN \\ anna.lacerda@hotmail.com
}

\section{RESUMO}

Este trabalho discute a apropriação, por uma professora, de aspectos da Teoria da Atividade e sua relação com o ensino de História. Seu objetivo é refletir sobre essa teoria, na perspectiva de Alexei Nicolaievich Leontiev, e a contribuição desse aporte teórico na formação dessa professora e as possibilidades formativas que ele apresenta para pensarmos o processo de ensino e de aprendizagem da História. Tratar-se de uma intervenção no processo formativo dessa docente que leciona História, nos anos finais do Ensino Fundamental, na Escola Estadual Coronel Fernandes, no Estado do Rio Grande do Norte. Os dados empíricos foram construídos durante a realização de Ciclos de Estudos Reflexivos ancorados na pesquisa colaborativa. Os resultados sugerem que as reflexões construídas, pela professora, manifestam uma compreensão da Teoria da Atividade e a sua contribuição para o processo de ensino e de aprendizagem da História, no nível fundamental. Esse entendimento porta uma perspectiva de mudança na sua atuação docente no sentido de desenvolver um ensino comprometido com a formação integral do educando. Palavras-chave: Teoria da Atividade. História. Ensino. Aprendizagem.

\section{THEORY OF ACTIVITY AND THE TEACHING OF HISTORY: TEACHING PERSPECTIVES AND LEARNING}

\begin{abstract}
This paper discusses the appropriation from aspects of Theory of Activity by a teacher and its relation to the teaching of History. Her goal is to reflect on this theory according to Alexei Nicolaievich Leontiev, and the contribution of the theoretical foundation in the training of this teacher and the formative opportunities he has presented to think about the History teaching and learning process. This is an intervention in the training of teacher who teaches history in the final years of elementary school, in Coronel Fernandes state school, in State of Rio Grande do Norte. The empirical data were constructed during the execution of Reflective Study Cycles anchored in collaborative research. Results have suggested that the ideas constructed by the teacher have manifested an understanding of Theory of Activity and its contribution to the teaching and learning process of History at the fundamental level. This understanding carries a prospect of change in her teaching performance to develop an education committed to formation of student.
\end{abstract}

Keywords: Theory of Activity. History. Education. Learning. 


\section{Introdução}

Nas últimas décadas intensificam-se estudos a respeito da forma pela qual o ensino da História vem se processando no interior das instituições escolares brasileiras. Produções recentes como as de Cabrini (2000), Fonseca S. (2005a, 2006), Cainelli e Schimidt (2005), Silva e Fonseca, (2007), Bezerra (2008), Pinsky e Pinsky (2008) dentre outras, e o papel desempenhado pela Associação Nacional de História - ANPUH através de sua participação em processos de elaboração de documentos nacionais, bem como, de suas publicações, são exemplos disso.

O conjunto dessas produções, os Parâmetros Curriculares Nacionais de História (1997, 1998), o estabelecimento das Diretrizes Curriculares para os Cursos de História (2002) e As Diretrizes Curriculares Nacionais para a Área de História e a Formação dos Professores para a Educação Básica (2001), ao lado das produções acima citadas, têm contribuído para o redimensionamento do ensino de História na prática cotidiana das escolas. Todavia, o ensino dessa disciplina ainda tem um longo caminho a trilhar, particularmente no tocante ao papel a ser desempenhado pelo próprio conteúdo para o desenvolvimento pleno do aluno.

Como forma de contribuir para a estruturação de um ensino de História empenhado com a promoção humana objetivamos, com esse trabalho, refletir sobre a Teoria da Atividade, na perspectiva de Alexei Nicolaievich Leontiev, e a contribuição desse aporte teórico na formação de uma professora que leciona essa disciplina e as possibilidades formativas que ele apresenta para pensarmos o processo de ensino e de aprendizagem da História no nível fundamental.

$\mathrm{O}$ trabalho se encontra organizado em quatro partes. Na primeira, fazemos uma discussão em torno da História escolar ressaltando o desenvolvimento do seu currículo, a partir dos anos 1970, o qual tem se constituído em objeto de debate e atenção de autoridades políticas e educacionais brasileiras. $\mathrm{Na}$ segunda, apresentamos alguns conceitos básicos da Teoria da Atividade e prosseguimos, na terceira, refletindo sobre algumas dificuldades presentes no ensino de História. Por último, nos detemos na análise acerca de uma reflexão realizada por uma professora de História que leciona no Ensino Fundamental (anos finais), na Escola Estadual Coronel Fernandes, no município de Luís Gomes, interior do Estado do Rio Grande do Norte. Para esse estudo nos utilizamos de dados construídos por ocasião do desenvolvimento do mestrado no Programa de PósGraduação em Educação da Universidade Federal do Rio Grande do Norte.

\section{A História escolar: alguns aspectos das mudanças verificadas em seu currículo}

Pensar a História e seu currículo requer um olhar, ainda que breve, sobre algumas transformações que vêm ocorrendo no cenário educacional a partir da década de 1970 . Nessa década, mudanças curriculares no ensino de $1^{\underline{0}}$ e $2^{\underline{0}}$ graus, ocorridas com a reforma $5692 / 71$, vieram inovar as formas de centralização e controle do ensino cujos conteúdos eram planejados e sistematizados pelos órgãos governamentais e suas equipes especialmente formadas para este fim. No ensino de História algumas mudanças relacionadas aos métodos e técnicas de ensino "[...] visavam adequar-se a determinado e reduzido conhecimento histórico, sem que essencialmente os conteúdos fossem alterados, mas apenas simplificados e resumidos." (BITTENCOURT, 2008, p. 99). 
Nos anos 1980, amplia-se a abertura da economia para a inserção no mercado do grande capital internacional. As teses conservadoras do liberalismo ressurgem expressas nas idéias da liberdade de mercado, da minimização da esfera pública, da competitividade e do tolhimento dos direitos sociais. As demandas por educação ampliam-se, estendendose a todos os níveis educacionais e propostas, quanto à nova Lei de Diretrizes e Base da Educação Nacional, passam a ser construídas.

Acontece uma reformulação curricular em estados e municípios brasileiros para o Ensino Fundamental e Médio referente à História. Os conhecimentos escolares passaram a ser redefinidos, ocorrendo um amplo debate nacional em torno do pensar a História como disciplina autônoma, visando revalorizá-la como campo de saber fundamental para a formação crítica dos cidadãos. Há um destaque à relevância dos conteúdos sociais e culturais a eles associados ideários políticos, valores e comportamentos. Para Fonseca S. (2006) esse movimento se deu na articulação com o debate acadêmico em nível internacional, em torno do qual se articularam diversas abordagens historiográficas discutidas na Europa e Estados Unidos.

$\mathrm{Na}$ década de 1990, tornam-se evidentes as exigências decorrentes de uma nova configuração mundial atrelada às inovações tecnológicas e ao processo de globalização da economia a qual, como assinala Oliveira (2001), se caracteriza como uma nova forma de ditadura do mercado ou do capital das megacorporações sob as bases das reformas neoliberais.

Acompanhando o movimento internacional de ênfase no resgate da educação no nível fundamental ocorre a Conferência Mundial sobre Educação para Todos, realizada em 1990, em Jomtien na Tailândia, em cuja ocasião se elaborou a Declaração Mundial sobre Educação para Todos que se constituiu como um referencial para as políticas educacionais na América Latina e Caribe.

Em seguida veio a elaboração e aplicação do Plano Decenal de Educação para Todos (1993), a aprovação da Lei de Diretrizes e Bases da Educação Nacional - 9394/96, os Parâmetros Curriculares Nacionais para o Ensino Fundamental (1997, 1998) entre outros documentos.

Frente aos avanços tecnológicos, à reestruturação do sistema de produção e as modificações operadas no papel do estado, o governo brasileiro vem implementando políticas cujo projeto educacional atribui à educação um papel central no desenvolvimento econômico. Nesse contexto, os currículos escolares são objetos de muitas análises, considerando seu significado político e social, bem como, o papel que cabe a cada disciplina desempenhar na sociedade contemporânea. Há uma exigência de qualificação visando a adequação da educação à globalização das economias, as atuais políticas públicas e aos impactos das novas tecnologias e comunicações ao lado da demanda da construção de uma nova pedagogia. Os professores das várias áreas se vêem impelidos a mudar sua prática para acompanhar o que ocorre em âmbito global.

No processo de renovação na historiografia brasileira, inspirada na nova história francesa e na historiografia social inglesa, nas últimas décadas do século XX ocorre a ampliação de temas, fontes e problemas e a discussão em torno dos modos de investigar e interpretar a história. Na organização do ensino, a História se apresenta como um campo de possibilidades cujo ponto de partida são os problemas da realidade social vivida, devendo ser problematizados e analisados criticamente por professores e alunos.

A partir do momento em que o debate sobre o ensino de História passou a considerar, cada vez mais, seus vínculos com a produção historiográfica as propostas curriculares passaram por avaliações e outras foram surgindo, como as de caráter oficial ou formuladas na prática docente. (FONSECA, T., 2004). Essas iniciativas têm expandido a 
demanda por um ensino de História, até a atualidade, que não mais privilegie os fatos políticos singulares, os grandes nomes, a cronologia linear e a neutralidade do conhecimento.

Nos últimos anos, em meio às produções sobre a História escolar e publicações como as da Associação Nacional de História, a exemplo das Diretrizes Curriculares Nacionais para a área de História e a Formação dos Professores para a Educação Básica (2001) - que apresentam reflexões e críticas às diretrizes para formação de professores propostas pelo Ministério da Educação - vimos observando mudanças na forma de ensinar História às quais vêm se enriquecendo com os estudos no campo pedagógico.

Nesse sentido, destacamos os trabalhos sobre: a) a interdisciplinaridade (FAZENDA, 1993, 2003; SANTOMÉ, 1998; LUCK, 2003); b) o currículo (MOREIRA; SILVA, 1995; SACRISTÁN, 2000a, 2000b; SILVA, 2000; LOPES; MACEDO, 2002); c) a didática (LIBÂNEO, 1994; VEIGA, 1996), ZABALA, 1998, 1999) d) e a formação docente (NÓVOA, 1995; TARDIF 2008; PIMENTA, 2007).

Nessa interlocução com o conhecimento pedagógico, o conhecimento histórico escolar tem reformulado métodos de ensino, materiais didáticos, conteúdos, entre outros aspectos. O diálogo da História com essas produções e áreas de conhecimentos tem favorecido estudos de diferentes problemáticas contemporâneas.

Discussões em torno da necessidade de se ensinar o aluno a pensar/refletir vêm trazendo, desde a segunda metade do século XX, uma reflexão sobre os métodos tradicionais de ensino. Ideias, como a do aluno construindo o seu próprio conhecimento, têm sido consideradas em proposições curriculares e ações pedagógicas as quais, desde os anos de 1990, vêm sendo enriquecidas com os trabalhos de Freire (1980a, 1980b, 1983) no tocante à consideração das classes e grupos mais excluídos da sociedade.

Do exposto, entendemos que a constituição da História e a organização do seu currículo nas nossas escolas têm estado envolvidas em discussões políticas que se encontram em destaque, em momentos diversos, e do que é produzido cientificamente. Nesse processo vislumbramos impasses, espaço de luta e alguns aspectos de mudança que nos põem atentos e visionários de uma História que possa ser ensinada, possibilitando ao aluno ver a história humana como algo que lhe é próxima; fornecendo-lhe um entendimento de um devir histórico como possibilidade de perspectivas, realizações e desenvolvimento humano.

A Teoria da Atividade adotada no Brasil a partir da década de 1980, em continuidade às ideias de Vygotsky, vem colaborando para esse redimensionamento ao nos trazer a noção de natureza social da mente humana consubstanciada à atividade dos homens como força criadora de cultura.

\section{A Teoria da Atividade: alguns conceitos fundantes}

As escolas científicas, que se formaram na história da psicologia soviética, explicaram, de diferentes maneiras, uma série de problemas psicológicos específicos. Para os postulados da teoria Histórico-Cultural, da Teoria da Atividade e da Teoria da Assimilação das Ações Mentais o desenvolvimento psicológico do homem, suas funções mentais superiores forma-se na sociedade, no processo de apropriação dos produtos culturais criados pela humanidade. Fundamentadas na dialética materialista elas apresentam um entendimento de problemas psicológicos considerando a relação entre o funcionamento mental humano e o contexto sócio-histórico. ${ }^{1}$ 
Entender a relação entre o funcionamento mental humano e o contexto histórico e cultural representa um dos caminhos para uma compreensão do próprio homem e da realidade na qual ele se encontra inserido, pois enquanto se apropria do meio físico e sociocultural, através da atividade, o indivíduo transforma esse meio e transforma-se também.

A categoria fundamental dessa teoria é a atividade. Esse conceito foi desenvolvido por Leontiev $(1983,1989,2004)$ e diz respeito a

[...] uma unidade molar não aditiva do sujeito corporal e material. Num sentido mais estreito, ou seja, ao nível psicológico, esta unidade da vida é mediada pelo reflexo psíquico, cuja função real consiste em que este orienta o sujeito no mundo dos objetos. (LEONTIEV, 1983, p. 66, tradução nossa).

A atividade é um processo que inclui não somente manifestações externas observáveis como também internas e componentes mentais e se realiza através de um conjunto de ações e operações cuja significação social é derivada de ações e operações coletivas.

Na composição da Teoria da Atividade a psique é entendida como uma forma de atividade vital do homem o qual interage com o mundo, de modo ativo, cumprindo ações práticas externas e ações psíquicas. Como declara Talízina (1988, p. 30, tradução nossa): "A psique [...] é atividade, é um sistema de ações e operações unidas por um motivo e um objetivo." Essa natureza social da psique do homem evidencia que as capacidades do ser humano, seu pensamento, suas funções mentais se formam e se desenvolvem durante sua existência num processo de transformação de experiências sociais em pessoais.

A experiência histórica do gênero humano e suas capacidades intelectuais, que foram formadas nessa experiência, estão consolidadas nos objetos materiais e em fenômenos como linguagem, ciência, obras de arte, entre outros, criados pelo homem. Porém, como escreveu Leontiev (2004), será interagindo com o outro, num processo comunicativo, educativo que os indivíduos se apropriam, objetivam e reproduzem as capacidades, propriedades e procedimentos humanos, formados historicamente, realizando uma atividade cognoscitiva, adequada, ainda que não idêntica à atividade humana encarnada nas formas culturais (material e não-material).

Numa relação com o processo de ensino e de aprendizagem na escola nos diz Kostiuk (2007, p. 53): "O desenvolvimento das características intelectuais do aluno não poderá discutir-se de modo adequado se se prescindir do desenvolvimento de outras características (emotivas, volitivas, do caráter), quer dizer, da formação unitária da personalidade em desenvolvimento." Do exposto, compreendemos a importância que tem as motivações subjetivas, o interesse cognoscitivo, novos modos de raciocínio na atividade de aprendizagem de forma a ser gerada uma reflexão mais abrangente do fenômeno estudado e/ou em estudo.

Outra categoria importante na Teoria da Atividade se refere a apropriação que nas palavras de Leontiev (2007, p. 93): “[...] é um processo que tem como consequência a reprodução no indivíduo de qualidades, capacidades e características humanas de comportamento." Não se trata, portanto, de uma adaptação ao mundo dos objetos e fenômenos uma vez que o indivíduo "[...] faz deles seu, apropria-se deles." (LEONTIEV, 2007, p. 93). Esse apropriar-se dos objetos ou dos fenômenos construídos historicamente possibilita ao homem seu processo de hominização e sua individualidade.

No decurso do processo de apropriação dos produtos culturais, os quais expressam a síntese de toda a construção histórica da humanidade, o indivíduo poderá se apropriar e 
se objetivar neles sem uma consciência crítica do processo de desenvolvimento histórico desses produtos culturais. A educação escolar, então, tem um papel edificante para que a apropriação e a objetivação dos produtos culturais, pelo aluno, possam ocorrer de forma consciente. Nesse sentido, os dois aspectos da atividade psíquica: a aquisição de conhecimentos e a formação de ações mentais são potencializadoras do desenvolvimento do educando. As ações mentais são aqui entendidas como processos psíquicos que envolvem análise e síntese cuja aquisição consiste no fato de que essas ações mentais se convertem em hábitos manifestando-se com grande liberdade e facilidade. (BOGOYAVLENSKY, MENCHINSKAYA, 2007).

A Teoria da Atividade, no seu dinamismo, comporta as dimensões cognitiva e afetiva as quais precisam ser consideradas, atentamente, no processo de aprendizagem do aluno. No ensino de História isso requer, dentre outros aspectos o entendimento e o enfrentamento de vários desafios dos quais explicitamos alguns.

\section{0 ensino de História: problemáticas desafiadoras}

Ao longo do século XX a educação sofreu mudanças para atender às demandas sociais, políticas, econômicas, entre outras. No limiar desse século XXI com a intensificação e/ou reconfiguração das demandas anteriores, além do surgimento de outras, ao lado da intensa expansão das tecnologias de informação e comunicação e da vastidão do conhecimento é exigida uma educação que sinalize para um posicionar-se histórico do indivíduo para se beneficiar da produção gerada pelo trabalho humano, bem como, para produzir conhecimentos.

As escolhas dos conhecimentos a serem ensinados abrangendo, também um conjunto de valores, procedimentos, normas e atitudes precisam ser problematizadas ao lado da problematização da própria realidade. No entanto, na efetivação do ensino de História, ao longo do tempo, observamos algumas dificuldades como: a insuficiente vinculação entre o ensino de História e a promoção do desenvolvimento humano, a complexidade que envolve o processo de ensino e de aprendizagem de uma disciplina tão abstrata como é a História; o desenvolvimento de conceitos científicos e o nível de abstração presentes nessa ciência histórica.

Cuevas (2001), por sua vez, destaca algumas dificuldades as quais estão relacionadas ao contexto, ligadas a fatores como visão social da história, sua função política e a formação dos docentes. E acrescenta o fato do estudo da História supor o uso do pensamento abstrato formal em alto nível, devendo o aluno construir seu próprio conhecimento a partir de vestígios do passado que dão uma informação aproximada e, em certas ocasiões, de difícil elucidação.

Uma pesquisa realizada por Rocha (2007) nas áreas de História e Geografia, a partir de documentos de planejamentos (anuais, semestrais, bimestrais, mensais e de aulas) de dezenove escolas públicas da rede estadual que oferecem os anos iniciais do Ensino Fundamental, em catorze municípios do interior do Estado do Rio Grande do Norte (dentre os quais o da nossa investigação), revelou que no que se refere a esses documentos "os planos em geral, evidenciam uma dificuldade na distinção entre essas áreas, principalmente, quando tratam da seleção de conteúdos." (ROCHA, 2007, p. 641). E que neles são perceptíveis "[...] procedimentos na perspectiva de utilização de recursos de forma solta e isolada e, em geral, sem distinção tanto em relação ao nível de ensino, ao tipo de plano, como aos objetivos e conteúdos propostos." (ROCHA, 2007, p. 640). 
O aluno ingressa nos anos finais desse nível de ensino, apresentando muitas dificuldades de apreender a História escolar, pois é necessário uma certa compreensão para se dar uma explicação sobre por que um fato e/ou acontecimento ocorreu de uma determinada forma e não de outra. Algo desafiante a ser considerado como objeto de reflexão, tanto dos profissionais que lidam com esse ensino como dos que se encontram mais envolvidos com a pesquisa. Além dessas dificuldades, a nossa experiência com o ensino dessa disciplina é indiciaria de que grande parte dos alunos a consideram "fácil", justificando que para aprendê-la, necessitam apenas de "memorização" - referente à memorização mecânica ou de cor.

A História e o seu ensino, por sua vez, segundo Fonseca S. (2005b), são fundamentalmente formativos e os professores que trabalham com ela vivenciam uma situação ambígua uma vez que essa disciplina é extremamente valorizada, estratégica para o poder e a sociedade é, ao mesmo tempo, desvalorizada pelos alunos e por diversos setores do aparato institucional e burocrático.

Para a compreensão dos conhecimentos de uma disciplina é preciso um trabalho especial que implica, de acordo com Rubinstein (1977, p. 150), “[...] todos os processos nos quais o conteúdo científico objetivo se descobre nas suas relações recíprocas cada vez mais profundas e variadas." O ensino de História, como um exercício de interpretação do funcionamento das sociedades do passado e de seus problemas, ajuda a compreender a complexidade dos acontecimentos, dos fenômenos sociais, políticos entre outros, residindo aí uma das suas possibilidades formativas. Ademais,

Toda disciplina docente, toda atividade específica que se realiza, possui uma relação com o curso de desenvolvimento do aluno que pode variar de acordo não só com os estágios pelos quais o ser humano passa na vida como também com sua própria individualidade. Isso justifica o estudo detalhado de cada aspecto do conteúdo, de cada tema em particular, sob o ponto de vista da função que desempenha no desenvolvimento da personalidade integral do aluno. (NÚÑEZ, 2009, p. 137).

Dessa forma podemos compreender que as condições criadas para o desencadeamento do processo de ensino e de aprendizagem têm implicações diretas tanto na aprendizagem dos conteúdos específicos de uma disciplina como no desenvolvimento das ações mentais do aprendiz. São vários os itinerários didáticos e metodológicos que contribuem para que se operem as referidas mudanças. No caso particular do ensino de História, chamamos a atenção para as possibilidades que a Teoria da Atividade apresenta como perspectiva viável para que isso ocorra.

\section{A Teoria da Atividade e suas implicações no ensino de História: reflexões no processo de formação docente}

A preocupação com um processo de ensino e de aprendizagem da História que tenha como uma de suas finalidades a apropriação de conhecimentos e o desenvolvimento do aluno nos levou a realizar uma pesquisa durante o mestrado, no Programa de PósGraduação em Educação da Universidade Federal do Rio Grande do Norte, que resultou na dissertação intitulada: A História escolar e a Teoria da Atividade: relações $e$ possibilidades formativas no ensinar e aprender (2010).

Para a realização dessa pesquisa contamos com a participação da professora Dulce (codinome), graduada em História, que leciona essa disciplina nos anos finais do Ensino 
Fundamental, na Escola Estadual Coronel Fernandes, no município de Luís Gomes, no Estado do Rio Grande do Norte.

O desenvolvimento da empiria se deu em dois momentos relacionados com a presença da professora citada. O primeiro momento foi constituído pelos Ciclos de Estudos Reflexivos nos quais nos preocupamos com a fundamentação teórica a respeito da Teoria da Atividade e o segundo, de Sessões Reflexivas realizadas sobre aulas de História, no $8^{\underline{o}}$ ano, gravadas em vídeo.

O que apresentamos aqui compõe parte do material que foi produzido por ocasião dessa investigação. Para isso, fazemos um recorte de um dos momentos de formação sobre a Teoria da Atividade, ocorrido no decurso dos Ciclos de Estudos Reflexivos. Esses ciclos constituem um procedimento de investigação ancorado na Pesquisa Colaborativa, compreendendo

[...] um procedimento complexo de construção, (re) construção de conhecimento e do próprio processo cognoscitivo, uma vez que as análises e discussões neles vivenciadas oportunizam, além da reconstrução de saberes, a reconsideração de valores, crenças e objetivos de ação, propiciando a opção por alternativas mais eficazes à solução dos problemas vivenciados no cotidiano da prática pedagógica. (AGUIAR; FERREIRA, 2007, p.76)

Eles foram desenvolvidos em três etapas: sondagem das necessidades formativas da professora ( $1^{\underline{a}}$ etapa), apropriação de novos pressupostos teóricos ( $2^{\underline{a}}$ etapa) e reelaboração de conteúdos de aprendizagem ( $3^{\underline{a}}$ etapa). Ocorreram mediante a comunicação e a colaboração estabelecidas entre as partícipes (professora de História e pesquisadora), de modo a se configurar como uma forma de intervenção no processo formativo da professora visando a uma alternativa de mudança quanto ao seu saber-fazer em sala de aula.

$\mathrm{Na}$ etapa inicial, utilizamo-nos da entrevista semiestruturada através da qual evidenciamos algumas necessidades de aprimoramento da professora, tanto no tocante a promover uma maior participação do aluno na oralidade, durante o desenvolvimento das aulas de História, como o seu desconhecimento da Teoria da Atividade. A essa última necessidade formativa é que pretendemos nos deter mais especificamente sem, no entanto, desconsiderar a anterior.

No que se refere à segunda etapa, nela ocorreram os estudos de fundamentação teórica sobre a Teoria da Atividade numa relação com o ensino de História. Na terceira, que tem uma íntima relação com essa segunda, por ocorrer no decurso do seu desenvolvimento, se deu a reelaboração de conteúdos de aprendizagem.

Desenvolvemos treze encontros enfocando a teoria mencionada, totalizando uma carga horária de quarenta horas aulas. E é sobre um desses momentos de formação, ocorrido no dia 06 de maio de 2009, que refletiremos. Para apresentação do diálogo que se segue nos utilizamos do nome Da Paz (para a pesquisadora) e Dulce (para a professora de História).

Neste encontro de estudo, considerando que já havíamos discutido em encontros anteriores alguns textos de A. N. Leontiev, resolvemos trazer para dialogar com Dulce, um estudo dirigido no qual havia questionamentos sobre a Teoria da Atividade e a possibilidade de utilização de aspectos dessa teoria para um aprimoramento do ensino de História. Apresentamos à professora este estudo dirigido enfatizando a importância de retomarmos algumas discussões de modo a aperfeiçoar os aprendizados construídos.

Dentre estes questionamentos vamos nos deter no seguinte: Tendo em vista os aprendizados construídos sobre a Teoria da Atividade, bem como, a sua atuação como 
professora de História, que aspectos dessa teoria um professor de História, do Ensino Fundamental, poderia considerar para o aprimoramento de sua atuação em sala de aula?

Da Paz: - Você gostaria de começar a reflexão, Dulce?

Dulce: - Segundo Leontiev, a Teoria da Atividade pode contribuir com a formação do professor, juntamente com o aluno, num processo dialético, refletindo sobre o sistema das significações, ao longo da história, dentro da natureza das relações socioculturais onde as necessidades fluem inclusive a necessidade de apropriação do conhecimento.

Da Paz: - Sobre esse processo de apropriação do conhecimento, o que você teria a acrescentar ao que foi discutido em encontros anteriores?

Dulce: - Tem, em um dos textos que estudamos que a criança ao nascer está rodeada de um mundo objetivo criado pelo homem, onde ela se apropria desse mundo humanizado, desenvolvendo suas capacidades e funções mentais [...]. Eu entendi que na família ela começa a desenvolver seu processo cognoscitivo e, ao chegar à escola, vai desenvolver esse processo intelectual quando se depara com as atividades em sala de aula, quando se encontra em interação com outras crianças e diante do estudo, no convívio com os colegas e professores.

Da Paz: - Pensemos, então, no desenvolvimento cognoscitivo do aluno no processo de ensino e de aprendizagem da História...

Dulce: - O ser humano [...] é um sujeito ativo da história, do processo histórico, porque é o homem que faz cultura. O ser humano vai construindo a sua própria história e participando da história dos outros também... Se eu me proponho a dar um determinado conteúdo, mas não dou importância para a maneira como esse aluno está preparado para receber, se ele está interessado ou não, a forma como vai assimilar... Essa aprendizagem pode não ser satisfatória, porque eu não me preocupei em adquirir meios e estratégias; não me preocupei se ele aprendeu ou não.

Da Paz: - Considerando os aportes, estudados, da Teoria da Atividade teria algo que você poderia sugerir, dessa teoria, que pudesse ser utilizado na melhoria do ensino de História, nessa escola em que você trabalha?

Dulce: - Desenvolver o pensamento dos alunos, a sua capacidade de analisar e generalizar os fenômenos da realidade, fazendo progredir [...] a sua ação mental por meio do ensino de História.

Do exposto vemos que Dulce (2009) inicia sua fala se reportando à Teoria da Atividade na qual ela vê uma contribuição para a sua formação e a do aluno ocorrendo, assim, forma dialética, na reflexão sobre o sistema de significações construído ao longo da história humana. Ela percebe que nas relações socioculturais surgem necessidades, inclusive de apropriação do conhecimento.

Essa reflexão feita pela docente é bastante frutífera, pois na perspectiva da Teoria da Atividade é interagindo com o outro, num processo educativo que os indivíduos se apropriam do sistema das significações construídas historicamente, desvelam a natureza das relações reais do homem com o mundo gerando novas necessidades, faculdades, 
capacidades e uma nova estrutura de sua consciência, simultaneamente, à transformação das condições de vida.

No contexto da atividade docente isso requer do professor construir procedimentos, estratégias de ensino dentre outros elementos e mediar o processo de ensino e de aprendizagem de modo a viabilizar o aprendizado do aluno considerando os aspectos cognoscitivos, afetivos, históricos, de atitudes e de valores etc.

Numa relação com o exposto, na sua segunda fala, Dulce (2009) demonstra um entendimento da importância da escola no desenvolvimento cognoscitivo dos alunos no momento em que estes se deparam com o estudo, no convívio com colegas e professores.

A educação escolar é, conforme Talízina (1988), Leontiev (2004) e Vygotsky (2007, 2008), fonte de desenvolvimento psicológico do homem. Nesse sentido a atividade de ensino pode dirigir a atividade de aprendizagem do aluno de modo a lhe possibilitar organizar, ativamente, suas ações mentais e desenvolver funções psíquicas.

$\mathrm{Na}$ continuidade do nosso diálogo, dirigimo-nos à professora para que discorresse sobre o desenvolvimento cognoscitivo do aluno no processo de ensino e de aprendizagem da História. Ela iniciou expondo ser o homem um sujeito ativo da história o qual constrói a sua própria história participando, também, da história do outro. Em seguida, retratou o que pode ocasionar uma aprendizagem não satisfatória.

A fala inicial da professora partícipe apresenta uma relação com o materialismo histórico-dialético no qual se encontra respaldada a Teoria da Atividade. Para Leontiev (2004), Marx e Engels, (2005) são os homens, em atividade, que produzem a sua existência, mudam sua realidade, seu pensamento e os produtos do seu pensamento. Quanto ao segundo ponto da sua fala - referente à aprendizagem não satisfatória podemos observar que ela revela preocupações em torno da preparação do discente para o aprendizado do conteúdo, seu interesse e forma de assimilação. Acrescenta que sem a atenção do docente para com esses aspectos, a aprendizagem pode não ser satisfatória.

As preocupações de Dulce são procedentes, pois, de acordo com esse marco teórico, quando o aluno não se sente motivado a se apropriar de conceitos, conhecimentos, procedimentos, habilidades, hábitos e valores que o enriqueça como ser humano essa atividade se torna algo estranho à sua personalidade, ocorrendo um comprometimento na sua aprendizagem e desenvolvimento. Logo, despertar o interesse do aluno e motivá-lo para a ação constitui aspecto indispensável para a realização da atividade de estudo.

Quanto à atenção para com a forma de assimilação, estar atento às ações e operações que o discente se utiliza para resolver os problemas que lhe são apresentados possibilita ao professor usar determinadas estratégias, de modo a favorecer ao aluno a geração de um entendimento num nível mais elevado.

No aprendizado da História, como ciência, se faz necessário formas processuais, intencionais e organizadas de pensamento de modo que, em tal processo, ocorra uma compreensão da natureza da história real. Nessa direção é viável a atuação do aluno em tarefas de aprendizagem diversificadas - desenvolvidas por meio de ações e operações que lhe favoreçam aprender a organizar suas ações mentais. A mediação do professor é de fundamental importância possibilitando um trabalho com as fontes materiais, escritas, iconográficas e orais.

Considerando os aprendizados construídos sobre a Teoria da Atividade, Dulce (2009) sugere que para uma melhoria no ensino de História é importante considerar o desenvolvimento do pensamento do aluno, a sua capacidade de analisar e generalizar os fenômenos da realidade, desenvolvendo a sua ação mental.

Essa reflexão vai ao encontro de um dos aspectos relevantes da Teoria da Atividade que diz respeito ao caráter ativo da apropriação do conhecimento. (LEONTIEV, 2007). A 
aprendizagem precisa estar associada à capacidade de avanço no desenvolvimento cognoscitivo do discente e da formação da sua personalidade requerendo para isso uma organização da atividade de aprendizagem que como nos diz Vygotsky (2007) ative um grupo de processos de desenvolvimento.

No processo de aprendizagem, a capacidade de usar, de forma adequada, ações mentais como abstração, análise, síntese dentre outras, surge de acordo com Bogoyavlensky e Menchinskaya (2007, p. 74): “[...] como resultado de um exercício mais ou menos prolongado." Nesse sentido, colocar o aluno frente a situações-problema nas quais ele precise fazer uso dessas ações mentais bem como, aprender a desenvolver habilidades como explicar, interpretar e argumentar pode ajudar o aluno a ampliar sua compreensão da história, desenvolver-se e se considerar mais partícipe dela.

Do exposto, evidenciamos que a professora numa interação conosco e a partir de suas experiências pessoais e profissionais, de seus saberes e conhecimentos, foi se apropriando de aspectos da Teoria da Atividade e descobrindo possibilidades de contribuição dessa teoria na melhoria de sua atuação no desenvolvimento do ensino de História, no nível fundamental.

\section{Considerações Finais}

Pensar a atividade humana, nessa perspectiva teórica, é percebê-la como processo de transformação constante da natureza e do próprio homem. É entender que na relação entre o funcionamento mental humano e o contexto histórico e cultural há caminhos para uma compreensão do homem e da realidade numa perspectiva transformadora.

Com o estudo realizado refletimos sobre a Teoria da Atividade, em A. N. Leontiev, e a contribuição desse aporte teórico na formação de uma professora de História e as possibilidades formativas que ele apresenta para pensarmos o processo de ensino e de aprendizagem dessa disciplina.

Iniciamos fazendo uma discussão sobre a História e algumas mudanças verificadas em seu currículo, notadamente a partir da década de 1970, no contexto das modificações ocorridas na sociedade brasileira e no mundo. Registramos a necessidade de um currículo comprometido com as realizações humanas, numa exigência à construção de um juízo histórico atribuindo sentido aos fatos e acontecimentos.

Apresentamos alguns conceitos básicos da Teoria da Atividade como atividade, psique, apropriação e ações mentais os quais são relevantes no entendimento da relação do homem com o social e da produção de uma realidade objetiva portadora de características humanas.

Discutimos sobre algumas dificuldades presentes no ensino dessa disciplina que vêm requerendo, dos profissionais que lidam com o ensino dessa área e dos que se encontram mais envolvidos com a pesquisa, um enfrentamento consistente na busca de um processo de ensino e de aprendizagem que prime pelo desenvolvimento integral do educando cuja educação escolar constitui um espaço privilegiado.

Em se tratando do processo formativo da professora de História, ocorrido por ocasião do desenvolvimento dos Ciclos de Estudos Reflexivos, os resultados evidenciam que as reflexões construídas pela docente apresentam elementos que manifestam sua compreensão da Teoria da Atividade e a contribuição desse aporte teórico para o ensino de História no nível fundamental. Esse entendimento porta uma perspectiva de mudança quanto ao seu saber-fazer, no sentido de propiciar ao aluno o alcance de um maior nível de aprendizagem e desenvolvimento. 


\section{Referências}

AGUIAR, O. R. B. P.; FERREIRA, M. S. Ciclo de estudos reflexivos: uma estratégia de desenvolvimento profissional docente. In: IBIAPINA, I. M. L. M.; RIBEIRO, M. M. G.; FERREIRA, M. S. (Org.). Pesquisa em Educação: múltiplos olhares. Brasília: Líber Livro, 2007. p. 73-95.

ASSOCIAÇÃO NACIONAL DE HISTÓRIA. As diretrizes curriculares nacionais para a área de história e a formação dos professores para a educação básica. Informativo eletrônico, 28 dezembro de 2001. Diretrizes curriculares/ formação de professores. Disponível em <http://www.anpuhsp.org.br>. Acesso em: 27 jul. 2009.

BEZERRA, H. G. Ensino de história: conteúdos e conceitos básicos. In: KARNAL, L. (Org.). História na sala de aula: conceitos, práticas e propostas. 5. ed. São Paulo: Contexto, 2008. p. 37-48.

BITTENCOURT, C. M. F. Ensino de história: fundamentos e métodos. 2. ed. São Paulo: Cortez, 2008.

BOGOYAVLENSKY, D. N.; MENCHINSKAYA, N. A. Relação entre aprendizagem e desenvolvimento psicointelectual da criança em idade escolar. In: LEONTIEV, A. N. et al. Psicologia e pedagogia: bases psicológicas da aprendizagem e do desenvolvimento. Tradução Rubens Eduardo Farias. 4. ed. São Paulo: Centauro, 2007. p. 63-85.

BRASIL. Lei no 5692 , de 11 de agosto de 1971 . Fixa diretrizes e bases para o ensino de $1^{\circ}$ e $2^{\circ}$ graus, e dá outras providências. Presidência da República, Brasília, DF,12 ago. 1971. Disponível em: < http: //www.planalto.gov.br/CCIVIL/LEIS/L5692.htm>. Acesso em: 8 ago. 2009.

Plano Decenal de Educação para Todos. Brasília: MEC, 1993.

Lei $\mathrm{n}^{\mathrm{0}}$ 9.394, de 20 de dezembro de 1996. Estabelece as diretrizes e bases da educação nacional. Diário Oficial da União, Brasília, DF, 23 dez. 1996. Disponível em: < http: //www.cefetce.br/ ensino/cursos/médio/Lei.htm>. Acesso em: 8 ago. 2009.

Parâmetros Curriculares Nacionais: história e geografia. Brasília: MEC/SEF, 1997, 5 v. (1 a a $4^{\mathrm{a}}$ séries $)$.

Ministério da Educação e do Desporto. Parâmetros Curriculares Nacionais: história. Brasília: MEC/SEF, 1998. ( $5^{\text {a a }} 8^{\mathrm{a}}$ séries).

CNE. CES. Resolução n ${ }^{0}$ 13, de 2002. Estabelece as diretrizes curriculares para os cursos de história. Diário Oficial da União, Brasília, DF, 9 abr. 2002. Seção 1, p. 33.

CABRINI, C. et al. O ensino da história: revisão urgente. São Paulo: EDUC, 2000.

CAINELLI, M.; SCHIMIDT, M. A. Ensinar história, São Paulo: Scipione, 2005

CUEVAS, J. P. Dificuldades para la enseñanza de la historia en la educación secundaria. In:___ Enseñar História: notas para uma didáctica renovadora. Mérida: Junta de Extremadura, 2001. p. 35-51. Disponível em http:// www.ub.es/histodidactica. Acesso em 20 nov. 2008.

CAVALCANTE, M. P. A história escolar e a teoria da atividade: relações e possibilidades formativas no ensinar e aprender. 2010. Dissertação (Mestrado em Educação) - Universidade Federal do Rio Grande do Norte, Natal, 2010. 
FAZENDA, I. C. A. (Org.). Práticas interdisciplinares na escola. 2. ed. São Paulo: Cortez, 1993.

Papirus, 2003.

Interdisciplinaridade: história, teoria e pesquisa. 11. ed. Campinas -SP:

FREIRE, P. Educação como prática de liberdade. 11. ed. Rio de Janeiro: Paz e Terra, 1980a.

Extensão ou comunicação? 4. ed. Rio de Janeiro: Paz e Terra, 1980b.

Pedagogia do oprimido. 12. ed. Rio de Janeiro: Paz e Terra, 1983.

FONSECA, S. G. Didática e prática de ensino de História: experiências, reflexões e aprendizados. 4. ed. Campinas, SP, Papirus, 2005a.

Como nos tornamos professores de história: a formação inicial e continuada. In:

Didática e prática de ensino de História: experiências, reflexões e aprendizados.

4. ed. Campinas, SP, Papirus, 2005b. p. 59-87.

Caminhos da História ensinada. 9. ed. Campinas, SP: Papirus, 2006.

FONSECA, T. N. L. História e ensino de História. 2. ed. Belo Horizonte: Autêntica, 2004.

KOSTIUK, G. S. Alguns aspectos da relação recíproca entre educação e desenvolvimento da personalidade. In: LEONTIEV, A. N. et al. Psicologia e pedagogia: bases psicológicas da aprendizagem e do desenvolvimento. Tradução Rubens Eduardo Frias. 4. ed. São Paulo: Centauro, 2007. p. 43-62.

LEONTIEV, A. N. [1975]. Actividad, conciencia, personalidad. Tradução Librada Leyva Soler, Rosario Bilbao Crespo e Jorge C. Potrony Garcia. La Habana: Pueblo y Educación, 1983.

El problema de la actividad em la psicologia. In: MASVIDAL, F. Temas sobre la actividad y la comunicación. Habana: Editorial de Ciencias Sociales, 1989. p. 259-298.

. [193-?]. O desenvolvimento do psiquismo. Tradução Rubens Eduardo Frias. 2. ed. São Paulo: Centauro, 2004.

Os princípios do desenvolvimento mental e o problema do atraso mental. In:

LEONTIEV, A. N. et al. Psicologia e pedagogia: bases psicológicas da aprendizagem e do desenvolvimento. Tradução Rubens Eduardo Frias. 4. ed. São Paulo: Centauro, 2007. p. 87-105.

LIBÂNEO, J. C. Didática. São Paulo: Cortez, 1994.

LOPES, A. C.; MACEDO, E. (Org.). Currículo: debates contemporâneos. São Paulo: Cortez, 2002.

LUCK, H. Pedagogia interdisciplinar: fundamentos teórico-metodológicos. 11. ed. Petrópolis, RJ: Vozes, 2003.

MARX, K.; ENGELS, F. A ideologia alemã (Teses sobre Feuerbach). Tradução Silvio Donizete Chagas. 8. ed. São Paulo: Centauro, 2005.

MOREIRA, A. F. B.; SILVA, T. T. Currículo, cultura e sociedade. 2. ed. São Paulo: Cortez, 1995.

NÓVOA, A. Os professores e a sua formação. Lisboa: Dom Quixote, 1995. 
NÚÑEZ, I. B. Vygotsky, Leontiev, Galperin: formação de conceitos e princípios didáticos. Brasília: Liber Livro, 2009.

OLIVEIRA, F. de. A nova hegemonia burguesa no Brasil dos anos 90 e os desafios de uma alternativa democrática. In: FRIGOTTO, G.; CIAVATTA, M. Teoria e educação no labirinto do capital. Petrópolis, Vozes, 2001.

PIMENTA, S. G. (Org.). Professor: identidade e trabalho docente. In: Saberes pedagógicos e atividade docente. 5. ed. São Paulo: Cortez, 2007. p. 15-34.

PINSKY, J.; PINSKY, C. B. O que e como ensinar: por uma história prazerosa e consequente. In: KARNAL, L. (Org.). História na sala de aula: conceitos, práticas e propostas. 5. ed. São Paulo: Contexto, 2008. p. 17-36.

ROCHA, V. M. L. C. História e Geografia nos anos iniciais do ensino fundamental: planejamento e identidades em questão. In: I JORNADA DE ESTUDOS E PESQUISAS EM EDUCAÇÃO E PLANEJAMENTO DE ENSINO, 2007, Pau dos Ferros. Anais...Pau dos Ferros: UERN, 2007. 1 CD-ROM.

RUBINSTEIN, S. L. Princípios de psicologia geral: a activação, a actividade. Tradução Jaime Carvalho Coelho. Lisboa: Estampa, 1977.

SACRISTÁN, J. G. O currículo: os conteúdos do ensino ou uma análise da prática? In: ; GÓMEZ, A. I. P. Compreender e transformar o ensino. Tradução Ernani F. da Fonseca Rosa, 4.ed. Porto Alegre: ArtMed, 2000a. p. 119-148. O currículo: uma reflexão sobre a prática. Tradução Ernani F. da Fonseca Rosa. Porto Alegre: ArtMed, 2000b.

SANTOMÉ, J. T. Globalização e interdisciplinaridade: o currículo integrado. Tradução Cláudia Schilling. Porto Alegre: Artes Médicas Sul, 1998.

SILVA, M.; FONSECA, S. G. Ensinar história no século XXI: em busca do tempo entendido. Campinas, SP: Papirus, 2007

SILVA, T. T. Documentos de identidade: uma introdução às teorias do currículo. 2. ed. Belo Horizonte: Autêntica, 2000.

TALÍZINA, N. F. [1984]. Psicologia de la enseñanza.Tradução Ana Clavijo. Moscu: Progresso, 1988.

TARDIF, Maurice. Saberes docentes e formação profissional. 9. ed. Petrópolis, RJ: Vozes, 2008.

VEIGA, I. P. A. (Org.). Didática: o ensino e suas relações. 4. ed. Campinas, SP: Papirus, 1996.

VYGOTSKY, L. S. Aprendizagem e desenvolvimento intelectual na idade escolar. In: LEONTIEV, A. N. et al. Psicologia e pedagogia: bases psicológicas da aprendizagem e do desenvolvimento. Tradução Rubens Eduardo Frias. 4. ed. São Paulo: Centauro, 2007. p. $25-42$.

A formação social da mente: o desenvolvimento dos processos psicológicos superiores. Tradução José Cipolla Neto, Luís Silveira Menna Barreto e Solange Castro Afeche. 7. ed., 2. tiragem. São Paulo: Martins Fontes, 2008.

ZABALA, A. A prática educativa: como ensinar. Tradução Ernani F. da F. Rosa. Porto Alegre: ArtMed, 1998. 
(Org.). Como trabalhar os conteúdos procedimentais em aula. Tradução Ernani Rosa. 2. ed. Porto Alegre: Artes Médicas Sul Ltda, 1999.

Notas

${ }^{1}$ Embora a ênfase do aporte teórico deste trabalho esteja na Teoria da Atividade de A. N. Leontiev entendemos essas teorias se enriquecendo e se fortalecendo mutuamente.

Artigo recebido em: 03/11/2009

Aprovado em: $\quad 31 / 5 / 2010$ 